\title{
P360: Materiovigilance and improvement of the maintenance of the biomedical equipment by the implementation of strategies for the use of equipment: case study of the hospital Gabriel Touré of Mali
}

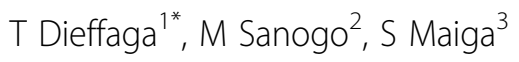

From 2nd International Conference on Prevention and Infection Control (ICPIC 2013)

Geneva, Switzerland. 25-28 June 2013

\section{Objectives}

To make the inventory of current practices for the use of the large equipment at the hospital Gabriel Touré and to bring solutions for an improvement of the use and productivity of the equipment.

\section{Methods}

This was a cross-sectional study using the method of problem resolution by quality improvement. It was conducted in 2004in two engineering departments of the hospital Gabriel Touré. 38 users of the equipment were concerned with the investigations.

\section{Results}

Of 38 surveyed persons only two doctors could operate the echograph. 3 persons of $38(7.89 \%)$ were abele to select the right parameters for the use of the equipment. Test of use is not carried out by 20 agents (52.63\%), including 11 persons that manipulate equipment of sterilization and medical imagery. 14 agents carry out the act badly including 5 technicians' that manipulate radiograpies what explains the important loss of simages. Only 8 agents $(21.05 \%)$ turn the equipment off after work. 18 agents do not carry out maintenance of the material after use including 9 users of radiography and echography.

'Hospital Gabriel Touré, Bamako, Mali

Full list of author information is available at the end of the article

\section{Conclusion}

The problem of maintenance at the hospital Gabriel Touré is a crucial question. The constraints related to the management of the large equipment at the hospital Gabriel Touré relate to several spects: the deficit of information, the absence of supervision and framing, the insufficiency of sensibilzation, the deficit of the actors implied in information and adapted know-how, the weakness of financial means and material allocated, the insufficiency of clear and codified directives fixing the conditions of use of the equipment. We recommend an internal reorganization of the service of maintenance, the programming of regular supervision, the development and the implementation of the management tools of maintenance.

\section{Disclosure of interest}

None declared.

\section{Author details}

${ }^{1}$ Hospital Gabriel Touré, Bamako, Mali. ${ }^{2}$ Medecine Faculty, School of Public Health, University of Montreal, Montreal, Canada. ${ }^{3}$ Faculty of Medicine, Pharmacy and Dentistry, Bamako, Mali.

Published: 20 June 2013

doi:10.1186/2047-2994-2-S1-P360

Cite this article as: Dieffaga et al.: P360: Materiovigilance and

improvement of the maintenance of the biomedical equipment by the implementation of strategies for the use of equipment: case study of

the hospital Gabriel Touré of Mali. Antimicrobial Resistance and Infection Control 2013 2(Suppl 1):P360.

(c) 2013 Dieffaga et al; licensee BioMed Central Ltd. This is an Open Access article distributed under the terms of the Creative Commons 